\title{
MOVILIZACIONES Y OPORTUNIDADES POLÍTICAS EN NiCARAgUA. UN DEBATE DESDE EL FEMINISMO
}

\author{
Mobilization and Political Opportunities in Nicaragua. A Feminist Debate \\ Simone da Silva-Ribeiro-Gomes
}

Resumen: En este texto se abordan las estructuras que ofrecen oportunidades políticas en Nicaragua y a partir de ellas se analizan los procesos de repolitización de los jóvenes. Se discuten las repercusiones de la despolitización electoral y de la repolitización sandinista, así como la ausencia de oportunidades para las mujeres. Existen tensiones y posibilidades para la juventud, la cual no se identifica con el proyecto sandinista actual aunque reconoce la Revolución Sandinista como un referente importante. La discusión parte de un trabajo etnográfico realizado en tres ciudades del país - Managua, León y Chinandega - durante las elecciones presidenciales de 2016, y de entrevistas con jóvenes feministas.

Palabras clave: feminismo, participación juvenil, movimiento social.

Abstract: This text discusses the structures that offer political opportunities and how the latter have led to the re-politization of young people in Nicaragua. We deliberate on the repercussions of an electoral de-politization and Sandinista re-politization, as well as the absence of opportunities for women. There are tensions and possibilities for young people, who do not identify with the current Sandinista regime, even as they consider the Sandinista Revolution to be an important reference. Discussion also centers on an ethnographic study done in three Nicaraguan cities, Managua, León, and Chinandega, during the 2016 presidential elections, and on interviews with young feminists.

Keywords: feminism, youth participation, social movement.

Simone da Silva Ribeiro Gomes. Doctora en Sociología por el Instituto de Estudos Sociais e Políticos de la Universidade do Estado do Rio de Janeiro, Brasil. Temas de especialización: violencia política, narcotráfico, movimientos sociales y feminismo. Correo electrónico: s.ribeirogomes@gmail.com.

Enviado a dictamen: 6 de diciembre de 2017 Aprobación: 20 de marzo de 2018 Revisiones: 1 
L a noche del 6 de noviembre de 2016 en que se confirmó la tercera elección de Daniel Ortega, del Frente Sandinista de Liberación Nacional (FSLN), como presidente de Nicaragua, la arteria principal de la capital del país, la Avenida 19 de Julio, estaba casi vacía; sólo unas pocas personas celebraban la noticia. Esto no es un dato menor si se recuerda que, en esa misma avenida, en 1979 habían marchado los jóvenes del FSLN con sus banderas rojinegras, vencedores en la guerrilla popular (Zimmermann, 2006). La diferencia, según Rosa, activista feminista de 28 años y oriunda de Chinandenga, residía en que, mientras antes las numerosas manifestaciones del sandinismo tenían lugar por las mañanas, entonces se llevaban a cabo de noche, cuando la "magia" de las manifestaciones populares se pierde un poco. ${ }^{1}$

En el presente texto se busca problematizar las relaciones entre el movimiento social feminista y el actual gobierno del FSLN, signadas por una serie de crecientes divergencias desde 2006. La hipótesis que guía el análisis es que en los últimos años el sandinismo, en función de su alianza con la Iglesia católica, ha restringido las oportunidades políticas para las movilizaciones y protestas, incluso de aquellas personas que operan en su apoyo. Esa situación ha dificultado, particularmente, la organización de las jóvenes y la movilización de consignas feministas, a la vez que ha generado conflictos y una merma en la identificación de ese sector con el proyecto revolucionario sandinista. Eso, en una sociedad marcada por el catolicismo y la baja autonomía de los movimientos sociales frente al gobierno, menoscaba aún más la fortaleza de los principales cuestionamientos del feminismo tales como el derecho al aborto.

Inspirada en el enfoque de la Estructura de Oportunidades Políticas (EOP), un encuadre analítico iniciado en un texto de Eisinger (1973) y recuperado en 1991 por Charles Brockett para analizar las movilizaciones campesinas en Centroamérica, en esta investigación se apela a una estrategia metodológica cualitativa, basada en la realización de cuatro entrevistas semiestructuradas con activistas feministas y en diversos actos de observación participante desarrollados en tres ciudades de Nicaragua - León, Chinandega y Managua - en noviembre de 2016, durante el período previo a las elecciones presidenciales. Cabe mencionar que ese particular contexto ofreció una oportunidad muy atractiva para hacer trabajo de campo, por tratarse de una coyuntura que permitió problematizar las continuidades y rupturas de las EOP en procesos que, es necesario aclarar, remiten a transformaciones más amplias y de largo plazo, no circunscritas al juego político y electoral. En correspondencia con los objetivos de esta investigación, se entrevistó a cuatro activistas feministas jóvenes y a Dora María Téllez, 2 referencia del movimiento en ese país.

Los alcances del tema tratado no se limitan a la comprensión de la dinámica de los distintos movimientos feministas en Nicaragua, sino que el análisis planteado propone un examen de los cambios institucionales para los movimientos de mujeres después de una revolución. Para comenzar, se revisan detenidamente las ventajas de pensar en términos de oportunidades políticas en Centroamérica y su potencial a la hora de dar cuenta de las oportunidades y tensiones de una juventud que, como la nicaragüense, permanece desmovilizada, y más específicamente de las construcciones políticas de las jóvenes feministas.

\section{¿Por qué pensar en oportunidades políticas para el feminismo nicaragüense?}

En líneas generales, la teoría de las EOP busca comprender la influencia que ejerce el ambiente político en los movimientos sociales. En la primera conceptualización de Eisinger (1973), elaborada en el marco de las movilizaciones urbanas en Estados Unidos, el sistema político y los activistas se relacionan a través de un flujo de aperturas, puntos débiles y barreras. Para Tarrow (1994), las EOP son el conjunto de dimensiones del contexto político que facilitan o dificultan la acción colectiva, y presenta tres componentes principales: la estabilidad de los alineamientos políticos, la apertura o cierre de las instituciones políticas y la viabilidad de los aliados. Por su parte, Brockett discute la utilidad de las EOP para analizar los movimientos campesinos 
en Centroamérica entre 1960 y 1984, que buscaron un giro para escapar a las "democracias industrializadas" (Brockett, 1991: 253). Su definición de las EOP supone "la configuración de fuerzas en un (potencial o real) ambiente político que influencia lo que el grupo tiene como aserción de demandas políticas" (1991: 254).

Son muchas las particularidades del contexto nicaragüense que justifican la utilización de las EOP, sobre todo de aquellas relativas a la relación entre Estado y movimientos sociales, en particular el feminista, en la última década. En este texto se hace énfasis en un cambio entre un gobierno que supo tener aspiraciones revolucionarias, pero que en su búsqueda de perpetuarse en el poder utilizó los derechos de las mujeres como recurso negociable a la hora de lidiar con los sectores más conservadores de la sociedad.

Nicaragua es un ejemplo de un gran cambio de oportunidades. En 1979, con el triunfo de la Revolución Sandinista y el derrumbe de la dictadura de Somoza (1934-1979), se produjo una transformación muy significativa en el curso de la historia de ese país. Sin embargo, desde 2006 el "sandinismo revolucionario" parece insuficiente para pensar los cambios más lentos y graduales que influyen en los movimientos sociales en su nueva fase. El concepto de EOP resulta útil analíticamente, pero debe ser replanteado para evitar una mirada centrada sólo en las grandes transformaciones revolucionarias, que descuide los movimientos institucionales menos visibles.

En efecto, los pequeños cambios en el feminismo son decisivos para el análisis de movimientos menos visibles. Según Dora María Téllez, la Revolución Sandinista de 1979 abrió "una puerta, empujando cambios importantes para las mujeres, en cuanto a los temas relativos a la paternidad responsable, el matrimonio y el divorcio, reconocimiento de la unión de hecho". ${ }^{3}$ Sin embargo, ese ímpetu inicial fue perdiendo fuerza a lo largo de los años, como se verá a continuación.

La democratización formal ocurrida después del fin de la guerra debe entenderse con los aportes del feminismo, por la importancia de éstos en la transformación de los sistemas legales de la región, al incorporar la igualdad de género al menos como parte del discurso público. En términos de las EOP, el movimiento feminista habría aprovechado las condiciones en el período posconflicto y colocado los asuntos relativos a los derechos de las mujeres en el centro de los debates sobre la democracia, con lo que se logró el establecimiento de mecanismos nacionales como ministerios y secretarías, y la aprobación de leyes específicas de género. Sin embargo, esas relaciones entre el movimiento y el Estado son contingentes y se encuentran siempre sujetas a una redefinición constante (Sagot, 2014).

Inicialmente, a fines de la década de los setenta, el FSLN afirmaba en su discurso en relación con el feminismo la obligación del Estado de remover los obstáculos que impedían en la práctica la igualdad de todos los ciudadanos. En ese marco, los planteamientos del movimiento feminista parecían tener buena acogida. Entre ellos figuraban: la ampliación de la atención a las madres y a sus hijos; la eliminación de la prostitución; el establecimiento del derecho a igual protección por parte de las instituciones revolucionarias para los niños nacidos fuera del matrimonio; el derecho a dos meses de ausencia por maternidad antes y después del parto para las mujeres trabajadoras, y la elevación en el nivel político-cultural y vocacional de las mujeres mediante su participación en el proceso revolucionario. ${ }^{4}$

Sin embargo, el programa sandinista para las mujeres no pudo cumplirse. Según Gariazzo (1991), ello se debió a las consecuencias de la guerra por cuyos esfuerzos debieron limitarse los programas sociales, pero también a la oposición de derecha, al peso del clero y al machismo de algunos sectores del propio gobierno. Para Palazón Sáez (2007), en el discurso sandinista la opresión de la mujer se consideraba una consecuencia de la ideología de las clases dominantes y, por lo tanto, ya no existiría tras la liberación nacional. Esa visión hizo que, una vez instaurado el nuevo gobierno, se limitaran las oportunidades políticas para el feminismo cuando, según esa autora, el FSLN abandonó la agenda de género en función de las necesidades revolucionarias - como la defensa y la reforma agraria-, quedando el lugar de la mujer, aun en el periodo posrevolucionario, confinado a sus orientaciones más tradicionales. 
Además, a la hora de examinar el papel del feminismo y de otros movimientos sociales en Centroamérica debe siempre tenerse en cuenta el análisis de la violencia en la región, lo que en este texto es incorporado a partir de las EOP. El pasado de Nicaragua puede considerarse violento, sobre todo si se toma en cuenta que fue el país en el que se desplegó una de las dictaduras más largas de la historia latinoamericana, la dictadura somocista (1934-1979), y una guerra civil posterior contra la coalición contrarrevolucionaria (Martí i Puig, 1997). ${ }^{5}$

Actualmente, la violencia, en su forma de represión estatal, tiene que ver con el cierre de espacios para el diálogo y con una dinámica política en la que cualquier discordancia es percibida como "traición". Así, el FSLN se fue consolidando en el gobierno en un contexto de movilizaciones cada vez menos intensas, especialmente de trabajo, campesinas y feministas; sin embargo, la militancia había crecido en estos movimientos durante la segunda mitad de la década de 1970, lo que fortaleció el ascenso del FSLN (Torres-Rivas, 2011).

En la próxima sección se discute sobre las tensiones y oportunidades para el activismo feminista joven entre 2006 y 2016, una década de cambios y continuidades.

\section{Entre oportunidades y tensiones: revolución e inmovilización de la juventud feminista}

El día siguiente al de la victoria del FSLN en 2016, en la avenida principal de Managua se vendían playeras con la imagen del "comandante" Daniel, al lado de imágenes del Che Guevara. Eso puede considerarse un ejemplo de lo que Ramírez (1999) afirma respecto al discurso del gobierno del FSLN: a pesar de que Ortega y su gobierno cambiaron mucho en los últimos años, la retórica y las imágenes revolucionarias seguían siendo las mismas.

El FSLN se fundó en 1961, inicialmente como una organización guerrillera, con una identidad desarrollada sobre las bases teóricas del foquismo, el nacionalismo y el marxismo (Martí i Puig, 2010). Pasado el período revolucionario, en el que Ortega gobernó como parte de dos juntas de gobierno, el FSLN ganó sus primeras elecciones democráticas en 1984 y permaneció en el poder hasta 1990, cuando perdió las elecciones (Zimmermann, 2006).

En 2006, después de dieciséis años en la oposición, el FSLN volvió al poder apoyado en un pacto firmado con el expresidente Arnoldo Alemán, del Partido Liberal Constitucionalista (PLC), quien en 2003 había sido condenado a veinte años de prisión por lavado de dinero. En ese marco, Alemán fue liberado en un acuerdo de reforma de la Constitución (Ramírez, 1999).

Desde 2006, es posible observar una profunda desilusión en amplios sectores de la población con el "nuevo sandinismo", que, según Zimmermann (2006), puede ser explicada a partir de la huella dejada por las privatizaciones de la década de 1990, que tuvieron como beneficiarios a un conjunto de amigos y antiguos líderes del gobierno del FSLN. Por si eso fuera poco, antes de reasumir el gobierno en 2016, el FSLN tuvo que tomar distancia de un escándalo conocido como "la Piñata" $\mathrm{y}$ pedir cuentas a los responsables.

Más de veinte años después de la primera elección democrática, en vísperas de la victoria de FSLN el 6 de noviembre de 2016, Rosa comentaba: “iVos tenés fe que se cuenten los [votos] anulados? Yo no tengo ninguna", 7 lo que contrastaba con la creencia en el sandinismo del pasado que, según Torres-Rivas (2007), organizaba a las fuerzas sociales y fomentaba una sociedad civil actuante.

A pesar de que continúa movilizada, la sociedad civil ha perdido fuerza. Los elementos que en la Revolución aparecían como oportunidades y promesas, parecían en los años 2000 haberse vuelto tensiones irresolubles para los movimientos sociales, que debían enfrentar un proyecto neoliberal en marcha. Según Palazón Sáez (2007), el feminismo en Nicaragua necesitaba una nueva articulación independiente de los partidos - sobre todo del FSLN-, con una clara orientación autónoma de los movimientos de mujeres. Para la autora, la reivindicación de la autonomía se convirtió, en los últimos años, en la única alternativa capaz de dar cabida a una agenda feminista en la que las cuestiones de género no estén supeditadas a los intereses políticos.

En términos políticos, durante las elecciones de 2016 se escuchó nuevamente la vieja consigna de la 
"farsa electoral". De hecho, Elise, una joven feminista de 25 años de Managua, se refería a lo que creía había sido una sucesión de irregularidades electorales: "los partidos menores tenían un acuerdo antes de las elecciones para evidenciar las prácticas de Daniel, pero él se volvió contra ellos, sacó de la contienda a la coalición de partidos opositores con más caudal electoral". ${ }^{8}$ Desde 2016, en momentos en que el FSLN desarrolla su tercer período presidencial consecutivo, las elecciones han sido intensamente cuestionadas, tanto por las dificultades que el gobierno impuso a la oposición para presentar sus propuestas, como por la falta de observadores nacionales e internacionales. ${ }^{9}$

Así, lo que se pudo observar fue que, si bien las tensiones registradas en las escasas protestas en los últimos años contra las prácticas del FSLN tuvieron repercusión en un amplio espectro político, las oportunidades para realizar movilizaciones han sido fuertemente restringidas. Ello porque desde los años 2000 el FSLN se ha empeñado en desmovilizar las iniciativas ciudadanas que no controla, en particular al feminismo no alineado con el sandinismo.

Ana, de 22 años, feminista universitaria de León, comentó que: "los becarios y funcionarios del gobierno tienen que ir a las marchas, o los becarios pierden las becas, [dado que] allá ellos pasan listas". Dicho de otra forma, la movilización a favor del gobierno parece siempre funcionar, pero, en buena medida, según denuncian varios militantes, por coerción. Según esta entrevistada: "es un gobierno en que la gente no dice nada, tiene miedo, o estás en favor o contra, la represión no está tanto en la violencia, pero [sí] en las amenazas de perder el empleo". ${ }^{10}$

El resultado de esas tensiones es una aparente inmovilización de las jóvenes feministas. A esa relativa inmovilización contribuye también el resurgimiento de los discursos religiosos en el inicio del siglo XXI, que invoca el mantenimiento de los roles tradicionales de género. Según Sagot (2014), una serie de grupos religiosos ha empezado a ocupar los espacios dejados por el movimiento de mujeres en Centroamérica, y a establecer alianzas con los gobiernos para detener los avances que se venían dando, lo que ha obstaculizado las demandas del movimiento feminista, sobre todo en el terreno de los derechos sexuales y reproductivos.

La situación es aún peor si se recuerda que en la última década del siglo XX en varios países centroamericanos se crearon distintos espacios de participación popular, tendencia en la que Nicaragua poco avanzó. De hecho, desde el retorno de Ortega al poder en 2006 hubo una caída en el acceso a los recursos provenientes de la cooperación internacional, comandada por la Coordinadora del Consejo de Comunicación y Ciudadanía, la primera dama Rosario Murillo. Asimismo, se redujeron los espacios de participación cívica existentes y los que quedaron en pie fueron cada vez más politizados, es decir, devinieron en buena medida espacios de propaganda del régimen sandinista. ${ }^{11}$ Las escasas asociaciones civiles, como afirman Natal y Álvarez (2014), tuvieron una reducida capacidad de resistencia al gobierno sandinista, de manera que el pluralismo de la sociedad se vio profundamente afectado por el hostigamiento y la represión de aquellos actores sociales que no compartían la ideología del "nuevo sandinismo". En esas condiciones, el retroceso de los temas relativos a la igualdad de derechos para hombres y mujeres fue de la mano con la reducción de los espacios de acción de las organizaciones feministas (Sagot, 2014). En Nicaragua, la mayoría de los movimientos sociales y de las organizaciones no gubernamentales se distanciaron del orteguismo desde las elecciones de 2011.

Sin embargo, preciso es reconocer que el FSLN introdujo una serie de mejoras contundentes en las condiciones de vida de las personas con menos recursos en las zonas rurales y urbanas a partir de sus políticas sociales focalizadas en la lucha contra la pobreza. Buena parte de esas personas son mujeres. Sin embargo, esas mejoras parecen estar en cuestión, a pesar de que el FSLN ha logrado un crecimiento económico y una relativa "pacificación" social, aunque no parecen estables y la represión estatal permanece como posibilidad cierta, como se percibió durante las protestas frente a las concesiones mineras en algunas comunidades.

En relación con las luchas feministas, Dora Téllez señaló que desde 1990 ha habido avances tales como: 
"la legislación para favorecer y asegurar el acceso de las mujeres a la tierra, para resolver con equidad los asuntos de maternidad y paternidad [... y] la paridad en las candidaturas de los partidos políticos". Sin embargo, el mismo régimen de Ortega fue el que "liquidó las Comisarías de la Mujer y la Niñez en la Policía Nacional, eliminando los equipos interdisciplinarios que se habían creado desde 1993". ${ }^{2}$

Para las mujeres jóvenes, uno de los principales problemas es la pobreza, lo que aumentaría las muertes por malnutrición, que podría ser paliada con atención médica o alimentación. Sin embargo, los programas gubernamentales Hambre Cero ${ }^{13}$ y Usura Cero, para los cuales sólo son elegibles mujeres bajo ciertos condicionantes, las benefician directamente. Además, hay una campaña por la alfabetización de las mujeres que igualmente las concierne (Morris, 2010).

\section{El feminismo histórico y las construcciones actuales de las jóvenes feministas}

Las oportunidades políticas para las mujeres antes de la Revolución eran escasas. El panorama, además del machismo tradicionalmente enraizado en la sociedad nicaragüense, incluía condiciones materiales de atraso en las que ellas ocupaban los trabajos peor pagados, además de que contaban con un acceso limitado a los servicios sociales. Mientras, apenas el 20\% de las adolescentes asistía a la escuela secundaria y el analfabetismo femenino rural llegaba al 93\%, en una sociedad en la que la mitad de las familias estaban encabezadas por mujeres. En 1974, el aborto había sido declarado ilegal y era aceptado solamente en situaciones clínicas, a pedido solamente del esposo o de un familiar cercano (Gariazzo, 1991).

En Nicaragua, existe debate sobre la génesis del movimiento feminista. Para Blandón (2016), el feminismo empezó en ese país en los años ochenta, después de la Revolución, basado en la crítica a la corrupción de una clase política, entendida como la principal causa de injusticias sociales. En ese sentido, los logros conseguidos en esos primeros años en materia social tuvieron una clara repercusión sobre las vidas de las mujeres. En ese período, la lucha provino de mujeres y hombres, de manera interclasista, en que las revolucionarias reconocieron el sistema de dominación masculino y sus efectos perversos sobre la vida de las mujeres. De hecho, uno de los lemas para la participación femenina en esa época fue: "No hay revolución sin emancipación de la mujer, no hay emancipación sin revolución".

Sin embargo, para Palazón Sáez (2007), el feminismo nicaragüense tuvo su inicio antes de la Revolución, con las organizaciones sufragistas en el siglo XIX, movilizadas hasta la década de los cuarenta, cuando las demandas del feminismo estuvieron bajo el amparo del gobierno somocista, que las retiró del espacio público, y sólo les dio cabida a partir del accionar del Ala Femenina del Partido Liberal Nacionalista (PLN), base de apoyo del gobierno dictatorial.

En la década de 1970, la defensa de los derechos humanos y el cuestionamiento del rol tradicional de madre fueron las demandas principales de las mujeres. Pronto se incorporaron mujeres a la resistencia de la guerrilla y el FSLN capitalizó la organización de las mujeres como forma de defensa civil (Palazón, 1970). En ese período, un gran número de mujeres nicaragüenses, de todas las clases sociales, se sumó a la política que hasta entonces había sido un espacio mayoritariamente masculino.

Según Molyneaux (1985), las mujeres llegaron a representar el 30\% de la fuerza de combate del FSLN, en una Revolución que se apropió del símbolo de la maternidad. Así lo ejemplifica el Comité de Madres de Héroes y Mártires, grupo del FSLN con una visión de la "madre sufrida y revolucionaria" (Chaguaceda, 2011). Junto a ese colectivo, en 1979 se creó la Asociación de Mujeres Nicaragüenses Luisa Amanda Espinoza (AMNLAE), todavía vinculada al FLSN.

Si bien en un primer momento el movimiento feminista se desarrolló en relación directa con el sandinismo, como en el ejemplo de la AMNLAE, oscilando entre la lealtad partidista y la defensa de los intereses feministas, en 1987 surgieron las primeras organizaciones fuera del sandinismo oficial, con 
secretarías de mujeres en las estructuras sindicales más independientes, además de otras organizaciones de mujeres autónomas. En 1990, tras la derrota en las elecciones del FSLN, las feministas plantearon sus demandas a los nuevos gobernantes, rompiendo su vínculo con este partido y afirmando una posición antimilitarista en la cual se desechaba cualquier jerarquía entre los géneros (Küppers, 2001).

El avance de los gobiernos neoliberales desde 1990 significó, como reacción, una mayor organización de las resistencias feministas, así como la politización de la violencia de género al interior del sandinismo, lo que provocó un cisma entre el sandinismo y el feminismo (Pirker, 2017). En ese momento, el feminismo se organizó en un ala más tradicional alrededor de la AMNLAE, y en otra más rupturista en torno al Movimiento Autónomo de Mujeres (MAM). ${ }^{14}$

Según Morris (2010), la denuncia en 1998 contra Ortega por abuso sexual a su hijastra Zoilamérica Narváez, hija de Murillo, fue un hito en el feminismo nicaragüense. En esa ocasión Murillo desestimó la acusación de su propia hija, en un intento por superar el escándalo. A pesar de que fue judicializado, el caso no prosperó debido a que la jueza a cargo decidió desestimarlo porque el delito había prescrito y porque Ortega gozaba de inmunidad en tanto expresidente. ${ }^{15}$ En 2002, después de una serie de intentos fracasados de proceder judicialmente contra Ortega, Zoilamérica presentó una denuncia ante la Comisión Interamericana de Derechos Humanos. ${ }^{16}$ Para Oettler (2009), ese caso constituyó un punto de inflexión en el movimiento feminista de Nicaragua, que se volvió más sensible a las prácticas sexistas dentro de la propia izquierda, prácticas consideradas por muchos como un síntoma secundario de lo que, aunque no deseable, se veía como parte de un "machismo sano".

Ante el retorno al poder del FSLN en 2006, uno de los ejemplos más palpables - y crueles- de los retrocesos en los derechos de las mujeres fue, sin lugar a duda, la prohibición del aborto terapéutico. Éste fue derogado a finales de $2007^{17}$ a partir de las peticiones y marchas realizadas conjuntamente por las Iglesias católica y evangélica. Además, el matrimonio religioso de Daniel Ortega y Rosario Murillo marcó la vinculación entre la Iglesia y el FSLN, y su asociación a una derecha conservadora.

Para Ramírez, semejante giro en la legislación, que castigaba el aborto terapéutico con varios años de cárcel, era parte de la conversión de Daniel Ortega al "catolicismo regresivo" (Ramírez, 1999: 24). En ese contexto, el intento de formar una Coalición Nacional de Mujeres Plural -integrada por sandinistas, liberales y sin partido- no se veía facilitado, e incluso fue saboteado por Arnoldo Alemán y la Iglesia católica, que veía en ella "una coalición de extranjeras y feministas" enarbolando espantajos de la moral social (Chaguaceda, 2011).

Sin embargo, la prohibición del aborto terapéutico funcionó como un estímulo para las jóvenes feministas, que se movilizaron públicamente a favor de ese derecho. Actores de la comunidad internacional se pronunciaron a favor de la restitución del aborto terapéutico con una persistente movilización social que, sin embargo, chocó con la negativa contundente del Estado. No obstante, esa movilización fue un hito en la historia de la lucha por los derechos de las mujeres en Nicaragua porque desató posibilidades de acción política en torno a los derechos de las mujeres y también en favor de la defensa de la laicidad del Estado, amenazada por el giro de la política oficial. Para Morris (2010), la prohibición significó un perjuicio particularmente gravoso para las mujeres más pobres, que no podían viajar hacia países vecinos para abortar. Dora Téllez complementa esa visión:

Hasta 2007, el movimiento de mujeres y feminista disfrutaba de libertad de organización y movilización, había experimentado un crecimiento sostenido de organizaciones de mujeres en todo el país que se dedicaban a temas de salud, violencia, empoderamiento de mujeres, justicia, producción y economía, etcétera. Desde la instalación de Ortega en el poder en 2007, el movimiento de mujeres ha sido perseguido, sus oficinas han sido allanadas por la policía, y desde Cancillería se han realizado gestiones para eliminar todo tipo de financiamiento y apoyo externo a los movimientos de mujeres. Ocho líderes 
del movimiento fueron acusadas penalmente y el proceso está aún abierto. Una radio de las mujeres de Jalapa, en el norte del país, fue robada e incautada por agentes policiales y del partido de Ortega, sin orden ni explicación alguna. Y así hay muchos casos [...] Los movimientos de mujeres, a pesar de la adversidad de este régimen, continúan manteniendo su movilización y denuncia. ${ }^{18}$

Desde entonces, los embates continuaron. En 2008 la policía de Managua, por órdenes de Ortega, decidió bloquear el paso de cuatrocientos activistas que pretendían marchar en la tradicional fecha del 25 de noviembre, Día Internacional por la Eliminación de la Violencia contra las Mujeres. De manera concomitante, hubo una procesión organizada y dirigida por Rosario Murillo de apoyo al gobierno del FSLN. ${ }^{19}$ Ese mismo año, en un ejemplo más de la arremetida conservadora, el gobierno sandinista realizó redadas en las oficinas del Movimiento Autónomo de Mujeres (MAM), acusando a los grupos de haber promovido abortos ilegalmente y de haberse involucrado en tratos financieros ilegales (Sargot, 2014).

Para las feministas del MAM, el FSLN se había convertido en una fuerza declaradamente hostil hacia las reivindicaciones feministas, y alineada con una parte de la derecha liberal y religiosa, inescindible de un sistema de poder corrupto (Lacombe, 2010). Desde 2006, el FSLN continúa con políticas restrictivas en materia de derechos sexuales y reproductivos. De acuerdo con el Movimiento Feminista de Nicaragua, se sigue utilizando el cuerpo de las mujeres para negociar cuotas de poder entre los poderes político, económico y religioso (Celiberti, 2016).

La consigna impulsada por Rosario Murillo desde 2006, "Nicaragua cristiana, socialista y solidaria”, ciertamente alejada de las viejas proclamas revolucionarias, también es cuestionada por las jóvenes feministas. Según Martí i Puig (2010), en los últimos años la primera dama ha adquirido cada vez más poder, lo que se presta a especulaciones sobre una posible sucesión presidencial. Sin embargo, Murillo despierta animadversión en la sociedad; gana posiciones pero sólo al precio de descalificar las luchas históricas de las mujeres de su país. En ese marco, lo que se pudo observar fue un contundente rechazo de las feministas a la figura de la primera dama porque aquéllas consideraban que lo que hacía en su ascenso a posiciones de creciente poder causaba, como afirma Elise, "dificultades al movimiento feminista, además de buscar sus intereses exclusivamente políticos". 20

Pero las feministas no sólo crítican los retrocesos en materia de género. Los pactos con las élites que perjudican las condiciones socioeconómicas de la población son también su blanco. Así, por ejemplo, Elise denunció las ventajas que obtenían "los amigos del FSLN, los empresarios". Sucede que los gobiernos de Ortega han sostenido una política de beneficios fiscales para ciertos tipos de inversión, conjugada con un salario mínimo bajo, además de una legislación laboral flexible. Ello, sumado a la elevada tasa de subempleo y empleo informal, dificulta las huelgas y las reacciones de los trabajadores. Asimismo, existen preocupaciones en materia institucional. Dora Téllez añadió que: "la subordinación del sistema judicial a las órdenes del orteguismo es un problema que afecta a los nicaragüenses en general, pero que repercute de forma particularmente grave en la vida de las mujeres". ${ }^{21}$

\section{Consideraciones finales}

A partir del análisis desarrollado a lo largo del artículo es posible ver cómo, en términos de EOP, en su nueva fase iniciada en 2006, el FSLN, de acuerdo con las élites del país, se ha consolidado como una fuerza con una cohesión suficiente para limitar fuertemente las oportunidades políticas de las feministas. De hecho, la inercia ya sería suficiente para el cierre de las EOP y así dificultar la movilización feminista, cuando la Revolución se institucionaliza y restringe las oportunidades para los activistas de forma más sutil que en los gobiernos dictatoriales.

El cruce entre feminismo y Estado, según Moberg (2005), se evidencia en la institucionalización de una Revolución, como aconteció en 1979 en Nicaragua, que condujo a la transformación de las organizaciones 
feministas en réplicas de prácticas políticas del FSLN, lo que se tradujo en la uniformidad de ideología, en verticalidad y en la presencia de dirigentes autoritarios. Para Palazón Sáez (2007), los movimientos de mujeres en ese país desde 2006 están revisando un proyecto capaz de pensar sus relaciones con el gobierno desde otro lugar que no sea ni dependiente, ni alineado.

El hecho de que el feminismo se haya organizado de forma más ostensiva en la década de 1980 comprueba la hipótesis de que las EOP cambiaron con la Revolución en 1979. Además, como en otras revoluciones nacionalistas, no implica que esas transformaciones conlleven instrumentos de liberación de la mujer. Se considera que la alianza del sandinismo con una derecha católica intransigente a partir de 2006 ha resultado en dificultades inéditas para la organización, lo que, sumado a los obstáculos gubernamentales y a la represión a los movimientos feministas autónomos, ha limitado de forma notable la fuerza de un feminismo fuera del "feminismo sandinista". Si la experiencia en el país fue diferente en comparación con lo ocurrido en otras revoluciones - como en la Revolución cubana, por ejemplo-, los derechos de las mujeres no dejaron de ser cuestionados, bajo la acusación de que eran "ideologías pequeñoburguesas", aunque, al menos en este caso, el feminismo no fue declarado ilegal ni llegó a calificarse de contrarrevolucionario.

Concluimos con la observación de que la nueva fase del sandinismo que inició en 2006 con Daniel Ortega sufrió una influencia más contundente del catolicismo, lo que generó protestas, sutilmente reprimidas, y resistencias más organizadas fuera del "feminismo oficial". El cambio de posicionamiento del gobierno del FSLN representó un intento de centralizar todas las pautas feministas en las organizaciones que comandaba, directa o indirectamente, interfiriendo en las EOP para las activistas, lo que provocó una escisión más fuerte entre el activismo joven autónomo que no se identificaba con las organizaciones de mujeres del FSLN.

Finalmente, en el país más pobre de Centroamérica, desde 2007 aumentaron las privatizaciones y la reforma del Estado, si bien las nuevas políticas sociales de lucha contra la pobreza no entraron en contradicción con las políticas neoliberales. Aunque la pobreza ha disminuido en Nicaragua, en el campo y entre los grupos minoritarios ésta continúa siendo alta. Las élites nicaraguenses, sin embargo, se han reconfigurado durante el período revolucionario y han resurgido en nuevos espacios, advenidos de la privatización de las empresas estatales. Para Sagot (2014), eso ha tenido influencia en los espacios de participación para las mujeres, restringiendo las condiciones, la amplitud y el contenido de esa participación. Las reformas neoliberales, en efecto, desarticularon la capacidad de organización no sólo de los campesinos y organizaciones de trabajadores, sino también de las feministas, lo que debilitó la fuerza de sus reclamos. Además, en términos generales esas políticas contribuyeron a consolidar una sociedad con elevados niveles de exclusión social (Sánchez-Ancochea, 2007) y a dejar las políticas de igualdad en el papel. En el discurso público puede reivindicarse la igualdad, pero no se incorpora como una dimensión inherente de la justicia social.

La situación desde 2006 no es la mejor. Como se observó en el presente texto, la apertura de las EOP que se produjo tras la Revolución de 1979 fue seguida de una creciente cerrazón. Las fuerzas feministas que habían contribuido al ascenso del sandinismo tuvieron, paradojicamente, un fuerte revés una vez producida la Revolución y, más particularmente, a partir de 2016, cuando se produjo la vuelta al poder del FSLN. En esas condiciones, las activistas que se mantienen fuera de las movilizaciones sandinistas se debaten entre la organización autónoma y los obstáculos y amenazas de un gobierno aliado a las fuerzas más retrógradas de la sociedad.

\section{Notas}

${ }^{1}$ Mi reconocimiento a Carlos de Jesús Gómez Abarca, Igor Daniel Palhares Acácio y Pedro dos Santos de Borba por las lecturas de versiones anteriores de este texto. Igualmente agradezco a las jóvenes que compartieron conmigo sus experiencias, cuyos nombres han sido cambiados para respetar la confidencialidad. 
2 Dora María Téllez, nacida en Matagalpa en 1955, fue comandante guerrillera, conocida por su presencia en la toma del Palacio Presidencial, en 1978, y por su desempeño como diputada. Es una de las principales referencias del feminismo en su país.

${ }^{3}$ Entrevista a Dora María Téllez, por correo electrónico, 28 de julio de 2017.

${ }^{4}$ Fuente: Resolución J.D. 07-2013 Aprobación de la Política de Género del Poder Legislativo. Disponible en: http://extwprlegsl.fao.org/docs/pdf/nicl36323.pdf (consultado el 12 de junio de 2017).

${ }^{5}$ La coalición contrarrevolucionaria, conocida como la Contra, que surgió en 1979 en Honduras, fue financiada por Estados Unidos y organizada en las zonas rurales, en una guerra que terminó en 1990, con más de 30000 civiles y 82000 militares muertos.

${ }^{6}$ El escándalo de la "Piñata" se desató en 1991, poco después de las elecciones de 1990 en las que el FSLN perdió el poder. Antes de su salida, los funcionarios del partido ordenaron una masiva transferencia de edificios, empresas, haciendas y acciones a las manos de un conjunto de terceros que quedaban en custodia de esos bienes para pasarlos luego al FSLN. Bajo la firma de los acuerdos de "concertación económica", en agosto de 1991, el FSLN obtuvo que una cuarta parte de esas empresas pasara a ser propiedad de los sindicatos sandinistas, a cambio de consentir el plan de ajuste monetario y la privatización de las empresas del Estado impulsado por el nuevo gobierno. En ese marco, los dirigentes de esos sindicatos pudieron enriquecerse $y$, en buena medida, "quedarse con todo". Tras semejante escándalo, hubo una escisión en el FSLN entre dos liderazgos en disputa, uno del entonces expresidente Daniel Ortega y el otro del exvicepresidente Sergio Ramírez, quien decidió fundar el Movimiento de Renovación Sandinista (MRS) en 1995.

${ }^{7}$ Entrevista a Rosa, Chinandega, 4 de noviembre de 2016.

${ }^{8}$ Entrevista a Elise, Managua, 5 de noviembre de 2016.

9 En términos nacionales, no participó el principal bloque opositor. La observación hecha por el Consorcio Panorama Electoral —compuesto por cuatro organizaciones: Ética y Transparencia, Instituto de Liderazgo de Las Segovias, el Movimiento de Mujeres
Chinandega y la Red de Mujeres Chontaleñas—divulgó un entorno restrictivo para la observación electoral, con una persistencia de los mismos defectos fundamentales en el proceso electoral que estuvieron presentes durante todo el periodo de observación, incluyendo tanto la falta de competencia real, de transparencia, de control y de equilibrio, como la utilización de vehículos del Estado y de edificios públicos para hacer campaña electoral.

${ }^{10}$ Entrevista a Ana, León, 7 de noviembre de 2016.

${ }^{11}$ Un ejemplo son los espectaculares, frecuentes en Nicaragua, en los que Daniel Ortega y Rosario Murillo aparecen como en propagandas disfrazadas: “ $¥$ DanielNicaragua, para avanzar-Cristiana, Socialista y Solidaria”.

${ }^{12}$ Entrevista a Dora María Téllez, por correo electrónico, 28 de julio de 2017.

${ }^{13}$ Lanzado en 2007, el Programa del Bono Productivo Alimentario o Hambre Cero experimentó una reducción en sus componentes a partir de 2011.

${ }^{14}$ Sin embargo, hay que aclarar que son varios los feminismos en el país, aunque en este artículo la caracterización es general. Uno de los movimientos de mujeres nicaraguenses es el costeño, distinto del feminismo del Pacífico, considerado más autónomo. Las organizaciones feministas de la Costa centran sus esfuerzos en el reconocimiento de sus derechos como pueblos indígenas y afrodescendientes, desde los primeros años de la década de los años 2000, y construyen alianzas y redes para demandar el reconocimiento de sus derechos.

15 Ver: http://www.bbc.com/mundo/noticias-americalatina-36969850 (consultado el 12 de abril de 2017).

${ }^{16}$ El asunto de la demanda contra Ortega también provocó reacciones fuera de Nicaragua. La primera ministra de Paraguay, Gloria Rubín, se manifestó públicamente contra la visita de Ortega a su país en 2008, pues lo consideraba un violador. Asimismo, múltiples protestas fueron organizadas en relación con la llegada de Ortega a diferentes países ese año. El escándalo trastocó la campaña de Ortega en 2011, alejando muchas figuras históricas al sandinismo.

${ }^{17}$ Además de Nicaragua, otros tres países han establecido una prohibición total del aborto, sin excepciones: Chile lo 
hizo en 1989, El Salvador en1997 y República Dominicana en 2009.

${ }^{18}$ Entrevista a Dora María Téllez, por correo electrónico, 28 de julio de 2017.

19 Ver:http://www.socialism.com/drupal-6.8/?q=node/329 (consultado el 12 de junio de 2017).

${ }^{20}$ Entrevista a Elise, Managua, 5 de noviembre de 2016.

${ }^{21}$ Entrevista a Dora María Téllez, por correo electrónico, 28 de julio de 2017.

\section{Referencias}

Blandón, María Teresa (2016). "Los cuerpos del feminismo nicaragüense”. En Juan Pablo Gómez y Camilo Antillón Najli (eds.), Antología del pensamiento crítico nicaragüense contemporáneo. Buenos Aires: CLACSO, pp. 353-370.

Brockett, Charles (1991). "The Structure of Political Opportunities and Peasant Mobilization in Central America". En Comparative Politics, 23(3): 253-274.

Celiberti, Lilian (2016), "Cuando la diestra es siniestra y la siniestra no es diestra”. En Nueva Sociedad. Democracia y Política en América Latina, noviembre. Disponible en:http://nuso.org/articulo/cuando-la-diestra-essiniestra-y-la-siniestra-no-es-diestra/ (consultado el 12 de julio de 2017).

Chaguaceda, Armando (2011). "El movimiento de mujeres y las luchas sociales por la democratización en la Nicaragua postrevolucionaria (1990-2010)". En Encuentro, 89: 39-62.

Eisinger, Peter (1973). "The Conditions of Protest Behavior in American Cities. En American Political Science Review, 67(1): 11-28.

Gariazzo, Alicia (1991). "La revolución no da la solución. La mujer en la Nicaragua sandinista”. En Nueva Sociedad. Democracia y Política en América Latina, 113: 51-58.

Küppers, Gaby (2001), “De la protesta a la propuesta... a la protesta?" En Género, feminismo y masculinidad en América Latina. San Salvador: Fundación Heinrich Böll, pp. 11-49.

Lacombe, Delphine (2010). ¿"Luchar contra el peor escenario"? Construcción del Movimiento Autónomo de Mujeres y debates de la militancia feminista en el contexto pre-electoral nicaragüense (2004-2006). Presentación para el congreso de la Asociación de Estudios Latinoamericanos LASA, Toronto, 6 a 9 de octubre.

Martí i Puig, Salvador (1997). La revolución enredada: Nicaragua, 1977-1996. Madrid: Libros de la Catarata.

Martí i Puig, Salvador (2010), "The Adaptation of the FSLN: Daniel Ortega's Leadership and Democracy in Nicaragua". En Latin American Politics and Society, 52(4): 79-106.

Moberg, Sarah(2005). “Elmovimientode mujeresyel Estado nicaragüense: la lucha por la autonomía". Independent Study Project (ISP) Collection, paper 437. Disponible en: http://digitalcollections.sit.edu/isp_collection/437.

Molyneaux, Maxine (1985). "Mobilization without Emancipation? Women's Interests, the State, and Revolution in Nicaragua”. En Feminist Studies, 11(2): 227-254.

Morris, Kenneth Earl (2010). Unfinished revolution: Daniel Ortega and Nicaragua' Struggle for Liberation. Illinois: Lawrence Hill Books.

Natal, Alejandro y Alberto Martín Álvarez (2014). La sociedad civil en Centroamérica a una generación del conflicto armado: ¿avances o retrocesos? Colima: Universidad de Colima.

Oettler, Anika (2009). "Nicaragua: orteguismo y feminismo”. En Iberoamericana, IX(33):178-181.

Palazón Sáez, Gema D. (2007). "Antes, durante, después de la revolución... la lucha continúa. Movimiento feminista en Nicaragua". En Lectora: Revista de Dones $i$ Textualitat, 13: 115-132.

Pirker, Kristina (2017). "Militancia sandinista y movilización socialen Nicaragua:laprofesionalización del compromiso". En Revue Internationale des Études du Développement, 2(230): 79-102.

Ramírez, Sergio (1999). Adiós muchachos. México: Alfaguara.

Sagot, Montserrat (2014). "La democracia en su laberinto. El neoliberalismo y los límites de la acción política feminista en Centroamérica". En Alba Carosio (coord.), Feminismos para un cambio civilizatorio. Caracas: Fundación CELARG, CLACSO y Centro de Estudios de la Mujer, pp. 40-66.

Sánchez-Ancochea, Diego (2007). "La globalización en países pequeños en desarrollo: Nicaragua en 
perspectiva comparada". En Revista Mexicana de Sociología, 69, abril-junio: 199-142. Disponible en: http:/www.redalyc.org/articulo.oa?id=32112596001 (consultado el 23 de noviembre de 2017).

Tarrow, Sidney (1994). Power in Movement: Social Movements, Collective Action and Mass Politics. Cambridge: Cambridge University Press.
Torres-Rivas, Edelberto (2007) "Nicaragua: el retorno del sandinismo transfigurado". En Nueva Sociedad, 207: 4-10.

Torres-Rivas, Edelberto (2011). Revoluciones sin cambios revolucionarios. Guatemala: F\&EG Editores.

Zimmermann, Matilde (2006). A revolução nicaraguense. Sao Paulo: Editora UNESP. 